\title{
Pessoa em Orpheu: para uma estética não aristotélica
}

Anderson Hakenhoarl

\begin{abstract}
Fernando Pessoa, in the voice of heteronym Alvaro de Campos, wrote an article entitled "Apontamentos para uma estética não-aristotélica", in which exposed part of his conception of art, defined in opposition to Aristotelian art. As Aristotle understood beauty as the main purpose of art, Pessoa said it is possible an art based on the idea of strength, not of beauty. In the article, the poems "Ode Triunfal" and "Ode Maritima", both of Campos, are examples of a non-Aristotelian art; however, another text of Pessoa explored this artistic design, it is the drama "O Marinheiro". The static drama, as Pessoa defined, reflects on the pretense as a creative act, the limits of drama, the poetic creation, the intersection between reality and dream, and thus can be understood as the theoretical discussion of the most important play for understanding heteronomy, which is materialized as a drama in which each character composes a poetic work. In this study, it is proposed to address the only dramatic text published in life by Pessoa as representative of his ideas about art. To establish these relations, this study starts from the art concept of Pessoa himself, which he calls "art of dreaming" to follow the ways of their aesthetic creations - namely Paulismo and the Interseccionismo - until the date of publication of the drama "O Marinheiro". The aim is to demonstrate here how the work of Pessoa evolved toward his conception of art to reach the drama "O Marinheiro", which is materialized as an example of this aesthetic and as a static drama, an essay for "drama in people".
\end{abstract}

Keywords: Fernando Pessoa; aesthetic; O Marinheiro.

Resumo: Fernando Pessoa, na voz do heterônimo Álvaro de Campos, escreveu um artigo intitulado "Apontamentos para uma estética não-aristotélica", no qual expôs parte de sua concepção de arte, definida em oposição à arte aristotélica. Enquanto Aristóteles entendia a beleza como a principal finalidade da arte, Pessoa afirmava ser possível uma arte baseada na ideia de força, não de beleza. No artigo, os poemas “Ode Triunfal” e "Ode Marítima", ambos de Campos, são os exemplos de uma arte não-aristotélica; entretanto, um outro texto de Pessoa explorava essa concepção artística, trata-se do drama "O Marinheiro". O drama estático, como Pessoa o definiu, reflete sobre o fingimento como ato criador, os limites do drama, da criação poética, da intersecção entre realidade e sonho, e, dessa forma, pode ser entendido como a discussão teórica sobre teatro mais importante para a compreensão da heteronímia, que se concretiza como um drama em que cada personagem compõe uma obra poética. Nesse estudo, propõe-se abordar o único texto dramático publicado em vida por Pessoa enquanto representante de suas ideias sobre arte. Para estabelecer essas relações, este estudo parte da concepção de arte do próprio Pessoa, a qual ele mesmo designa como "arte

1 Doutorando em Estudos Literários - Universidade Federal do Rio Grande do Sul 
do sonho", para seguir os caminhos de suas criações estéticas - a saber, o Paulismo e o Interseccionismo - até a data da publicação do drama "O Marinheiro". Busca-se demonstrar aqui como a obra de Pessoa evoluiu em direção a sua concepção de arte até chegar ao drama "O Marinheiro", que concretiza-se como exemplar dessa estética e, como drama estático, um ensaio para o "drama em gente".

Palavras-Chave: Fernando Pessoa; estética; O Marinheiro.

\section{Introdução}

O drama $O$ Marinheiro, de Fernando Pessoa, foi publicado na primeira edição da revista Orpheu. Inicialmente, Pessoa tivera intenção de publicá-lo na revista A Águia, porta-voz do grupo literário Renascença Portuguesa liderado por Teixeira de Pascoais, mas não obteve sucesso. Esse fato é certamente um fator relevante para o distanciamento de Pessoa da revista citada. Para sua publicação na revista que viria a ser o marco inicial do Modernismo em Portugal o drama foi reescrito por Pessoa, de modo que, depois de vinte anos, em carta a Casais Monteiro, o poeta afirma que o texto não o envergonhou nem o envergonhará.

Embora o teatro de Pessoa tenha sido deixado em segundo plano até a década de 1950 diante do fenômeno heteronímico, é digno de observação que a discussão artística de Pessoa sobre a criação heteronímia passa por sua produção dramática. Para Neves e Junqueira (2004), a heteronímia pessoana procede de uma reflexão sobre o teatro, seja pela questão do fingimento como ato criador, seja pela composição das relações entre os heterônimos no que Pessoa chamou de "drama em gente". Nesse sentido, O Marinheiro é antes um ensaio para a criação heteronímia do que uma tentativa de Pessoa de lançar-se como dramaturgo (vide o fato de que Pessoa publicou o texto em uma revista, ao invés de procurar realizar sua montagem cênica). Neste ensaio, Pessoa discute os limites do drama, da criação poética, da intersecção entre realidade e sonho e, principalmente, dos limites da arte aristotélica.

Segundo Aristóteles (2003), o drama é uma forma literária assentada na imitação (mímesis) das ações humanas, ou seja, é a palavra representada. O filósofo grego divide o drama em tragédia e comédia e ainda atribui uma finalidade a sua definição formal de tragédia, a capacidade de produzir a catarse. O filósofo grego declara que "a tragédia é a imitação, não de homens, mas de ações, da vida, da felicidade e da infelicidade (pois a infelicidade resulta também da atividade), sendo o fim que se pretende alcançar o resultado de uma certa maneira de agir, e não de uma maneira de ser" (2003, p. 36). A tragédia seria assim a representação do "que" e não do "quem". Aristóteles associa as ações da personagem a suas funções na intriga e não a identidade da personagem. Dessa forma, a beleza está na representação das ações, ou seja, na imitação.

Em oposição à estética aristotélica, Pessoa definiu $O$ Marinheiro como um drama estático. Suas características se identificam com o teatro simbolista dos anos 1890, no qual, ensina Gagliardi (2011), os diálogos muitas vezes não são senão intervalos que preparam o leitor para as pausas e os longos silêncios, e em que a encenação tem forte apelo simbólico. O grande nome do teatro desse período é o belga Maurice Maeterlinck, com o seu drama Os cegos (1890). Segundo Robert Bréchon (2000, p. 176-177), forneceu a $O$ marinheiro, seu "modelo formal da ação dramática". Assim define Pessoa o drama estático em nota datada de 1914: 
Chamo teatro estático àquele cujo enredo dramático não constitui acção — isto é, onde as figuras não só não agem, porque nem se deslocam nem dialogam sobre deslocarem-se, mas nem sequer têm sentidos capazes de produzir uma acção; onde não há conflito nem perfeito enredo. Dir-se-á que isto não é teatro. Creio que o é porque creio que o teatro tende a teatro meramente lírico e que o enredo do teatro é, não a acção nem a progressão e consequência da acção - mas, mais abrangentemente, a revelação das almas através das palavras trocadas e a criação de situações (...) Pode haver revelação de almas sem acção, e pode haver criação de situações de inércia, momentos de alma sem janelas ou portas para a realidade. (PESSOA, 1966, p. 113)

A leitura de Moisés (1988) é elucidativa nessa questão. O crítico afirma que Pessoa faz uma fusão entre uma forma teatral e um conteúdo poético. Essa fusão é o que Pessoa chama de "drama estático". Essa é, provavelmente, a discussão teórica sobre teatro mais relevante para a compreensão da heteronímia, que se concretiza como um drama em que cada personagem compõe uma obra poética. Para estabelecer essas relações, este estudo parte da concepção de arte do próprio Pessoa, a qual ele mesmo designa como "arte do sonho", para seguir os caminhos de suas criações estéticas até a data da publicação do drama $O$ Marinheiro.

\section{Movimentos Estéticos}

No início do século XX, buscando uma ideia que conduzisse a renovação artística na poesia portuguesa, Teixeira de Pascoais encontra na saudade um sentimento que considera tradicional na poesia do país. A partir disso, procura erguer uma nova filosofia estética, em que a saudade é vista como um privilégio do povo português e uma marca da evolução humana. Essa estética era o Saudosismo. Com amigos e colaboradores, forma em 1912 o grupo literário Renascença Portuguesa e a revista A Águia, que se torna porta-voz da almejada renovação literária do país. Segundo Lind (1970), Fernando Pessoa percebe que falta a Renascença Portuguesa um programa claramente definido e, ingressando na literatura portuguesa, publica três artigos na revista Á'guia em 1912, os quais demonstram sua evidente intenção de fornecer ao movimento de Pascoais o programa que lhe faltava.

Pessoa ingressa na literatura como ensaísta ao publicar Apontamentos para uma estética não-aristotélica, A nova poesia portuguesa socialmente considerada e A nova poesia portuguesa no seu aspecto psicológico. Apesar de seus ensaios serem dedicados ao Saudosismo, revelam sua preocupação com uma programação estética que sedimentasse a crítica literária da modernidade. Por isso, Lind (1970) afirma que a reflexão sobre a obra de arte precede nele o processo de criação artística. Nesses textos, Pessoa revela uma “obsessão" em aproximar as ideias estéticas da produção literária, a qual é realizada de maneira meticulosamente elaborada entre parte significativa dos poemas do heterônimo Álvaro de Campos e a estética sensacionista, por exemplo.

Os três ensaios não são crítica literária, mas textos programáticos, como já o denuncia a afirmação de Pessoa de que é possível por meio da observação da literatura de um certo país "prever ou concluir o que espera o país em que essa literatura é atual" (PESSOA, 1988 , p. 193). Isso demonstra que sua preocupação é com o futuro da literatura portuguesa, não com o presente. No texto "A nova poesia portuguesa socialmente considerada",

2 Fernando Pessoa parte da ideia de que todo grande movimento produz um grande poeta. Explora as épocas áureas da humanidade para exemplificar: a sociedade grega produziu um Homero, a Renascença produziu um Shakespeare. Portanto, partindo do pressuposto de que a Renascença Portuguesa inaugura uma nova 
Pessoa profetiza a iminência de uma época áurea da literatura portuguesa e o aparecimento de um Super-Camões, um poeta que será mais representativo do que Luiz Vaz de Camões. Para muitos críticos da obra de Pessoa, como Lind (1970) e Coelho (1980), o poeta português anuncia a si mesmo e a própria obra, tomando a profecia não como provocação, mas como meta para si mesmo.

No artigo intitulado "A nova poesia portuguesa no seu aspecto psicológico", Pessoa constata três características básicas na poesia saudosista: o vago, a sutileza e a complexidade. Embora essas características também estejam presentes na literatura simbolista francesa, Pessoa parece querer ter dito que esses três conceitos definem uma escola poética superior ao Simbolismo. Segundo Pessoa (1988), o vago é um objeto artístico consciente da nova poesia portuguesa. A isso, soma-se a sutileza, de forma que o poeta traduza "uma sensação simples por uma expressão que a torne vivida, minuciosa, detalhada [...] sem contudo lhe acrescentar elemento que se não encontre na direta sensação inicial" (p. 218). Por fim, a complexidade, que "traduz uma impressão ou sensação simples por uma expressão que a complica acrescentando-lhe um elemento explicativo, que, extraído dela, lhe dá novo sentido. A expressão sutil se intensifica, [...] a expressão complexa dilata, torna maior" (p. 219). Dessa forma, o processo sensitivo é intelectualizado. Conforme Lind (1970), apenas parcialmente essas afirmações se aplicam à poesia do Saudosismo; entretanto, aplicam-se perfeitamente a própria poesia de Pessoa, pelo menos a produzida do ano 1913 até o início de 1914, quando da criação dos heterônimos. As duas primeiras estrofes de "Hora absurda", datado de 04 de julho de 1913, bem demonstram que o poema se desenvolve a partir dos conceitos de vago, sutil e complexo.

O teu silêncio é uma nau com todas as velas pandas...

Brandas, as brisas brincam nas flâmulas, teu sorriso...

E o teu sorriso no teu silêncio é as escadas e as andas

Com que me finjo mais alto e ao pé de qualquer paraíso...

Meu coração é uma ânfora que cai e que se parte...

O teu silêncio recolhe-o e guarda-o, partido, a um canto...

Minha idéia de ti é um cadáver que o mar traz à praia..., e entanto

Tu és a tela irreal em que erro em côr a minha arte...

(PESSOA, 1942 apud ARQUIVO PESSOA, [200-a?], não paginado)

No poema, o silêncio da pessoa a quem se dirige o eu lírico é complicado pela imagem do barco com velas pandas, e, da mesma forma, o sorriso, pela brisa nas flâmulas. Modo de composição que se destaca é a complexidade, que, segundo Pessoa, é uma forma de dar um novo sentido a uma sensação por meio de uma expressão que a complica. Os dois, silêncio e sorriso, são metaforicamente comparados a escadas e andas supostamente usadas pelo eu lírico para se elevar a uma sensação de paraíso. Lind afirma que "o desdobramento de cada sensação em duas imagens correspondentes, para cada modo de sentir um objeto definido e palpável, é mantido tão conscientemente, que resulta na impressão de que as imagens se sucedem em ondas" (1970, p. 23).

O poema é subjetivo, os versos são vagos e sutis, aproximando-se da poesia simbolista, mas também complexos, já que são provocados a partir de um programa anteriormente

época áurea, profetiza a aparição, em Portugal, de um poeta que superaria até mesmo Camões. 
inventado. Essa complexidade implicada na elaboração das imagens presentes no poema é a diferença percebida para com os simbolistas segundo Lind, pois, para Pessoa, os simbolistas não são complexos. A exaltação do vago, da sutileza e da complexidade são prelúdios de suas próprias teorias: o Paulismo e o Interseccionismo ${ }^{3}$.

Entretanto, Pessoa afirma que a poesia saudosista também é objetiva, visto que escreveram poemas sobre a Natureza. Pessoa ainda salienta no mesmo ensaio uma característica de uma poesia objetiva: a plasticidade, definindo-a como "a fixação expressiva do visto ou ouvido como exterior, não como sensação, mas como visão ou audição”. Esta poesia plástica seria a poesia Greco-romana, a dos parnasianos e a de Cesário Verde. Lind confirma que Pessoa preocupa-se com a ideia da plasticização da arte (objetiva), tanto que a introduz na teoria neoclassicista, a qual atribui ao heterônimo Ricardo Reis.

Nessa discussão sobre o tema da poesia objetiva e subjetiva estão presentes os pilares da posterior evolução poética de Pessoa, tanto que atribui ao Super-Camões a missão de equilibrar a poesia subjetiva e objetiva, o que, para Lind (1970, p. 25), "efetiva-se na própria produção poética de Pessoa: Alberto Caeiro e Ricardo Reis tendem para a poesia objetiva; Álvaro de Campos e Fernando Pessoa ele mesmo, para a expressão subjetiva". Isso parece ser mais uma evidência de que Pessoa escreve mais sobre seus próprios ideais do que sobre os ideais do Saudosismo. Para dar existência ao Super-Camões, Gonçalves (1995) afirma que a multifacetação dos "eus" se torna obrigatória para Pessoa, e que este precisou de uma estética que "referendasse a nomeação de um poeta síntese" (1955, p. 112) em seu início de produção poética. A partir de 1913, Pessoa tenciona construir uma estética que viria ser a sua primeira tentativa de referendar a criação literária moderna: o Paulismo.

\subsection{Paulismo}

A estética paúlica provém de um poema datado de 29 de março de 1913, intitulado "Impressões do crepúsculo", que começa com a palavra pauis (de onde vem o nome Paulismo). Conforme Lind (1970), Paulismo significa poesia de paul ou pântano. O poema foi publicado no número único da revista $A$ Renascença, e é a primeira aparição de Fernando Pessoa como poeta português. Criado antes mesmo dos heterônimos, o Paulismo é a primeira aplicação da "arte do sonho", já que tem no sonho seu elemento fundamental, mantendo, assim, uma separação entre pensamento e ação.

João Gaspar Simões (S/D) afirma que Pessoa aplica no poema os princípios que havia descrito como sendo característicos da nova poesia portuguesa no artigo "A nova poesia portuguesa no seu aspecto psicológico", publicado pela primeira vez no número 9 da revista A Águia, em 1912. A partir disso, Lind (1970) observa que o vago, a sutileza e a complexidade estão presentes na poesia de Pessoa de forma programática. Gonçalves (1995), por sua vez, esclarece que o objetivo era ser uma estética onírica, um programa que considerasse a arte moderna uma transposição da realidade para o sonho. Assim, a linguagem poética tinha como objetivo a constituição de um "jogo" de significantes, entre o sentir e o pensar, entre a sinestesia e a escrita.

Como propagador de algumas características do Simbolismo, o Paulismo se utiliza de processos imagísticos que, de acordo Gonçalves (1995, p. 116), "fazem apelo às sensações mórbidas e requintadas, seja pela presença antitética, formal e conteudística, de imagens e impressões da natureza". Daí o próprio Lind (1970) afirmar que o poema "Im-

3 Cabe ressaltar que estas características são presentes também na estética sensacionista, como uma evolução natural do Interseccionismo, e praticada principalmente pelo heterônimo Álvaro de Campos. 
pressões do crepúsculo"4 concretiza a "concepção de Pessoa da arte do sonho estática" (p. 41), no sentido de que o Paulismo visava uma arte em que o significante (qualidades plásticas e estilísticas do poema) é privilegiado em relação ao significado, o sentido do poema. A programação estética paúlica previa, portanto, que as significações, os conteúdos, fossem inscritos a partir da imagem, por isso uma "arte de sonho estática".

O tema do poema - o tédio de viver - aparece no meio-verso "Tão sempre a mesma, a Hora!". O vago predomina no poema e de forma propositada, como nas expressões pauis de roçarem ânsias, as folhas que fitam o silêncio da alma, entre outras. A sutileza, que Pessoa entende como a tradução de uma sensação simples por uma expressão "que a torne vivida, minuciosa, detalhada [...], sem contudo lhe acrescentar elemento que se não encontre na direta sensação inicial" (PESSOA, 1988, p. 218), é percebida na utilização de imagens intensificadoras, como a uniformidade deprimente da Hora que se expressa no "balouçar de cimos de palma". A complexidade, de difícil distinção em relação à sutileza por ser, para Pessoa, uma tradução "duma impressão ou sensação simples por uma expressão que a complica, acrescentando-lhe um novo elemento explicativo que, extraído dela, lhe dá um novo sentido" (PESSOA, 1988, p. 219), é percebida em imagens como "alma em ouro", que designa a emoção da alma ao contemplar o pôr do sol, e "outono delgado", que expressa a delicadeza da estação aos olhos do eu lírico.

Lind (1970) vê que, na surpresa perante o tédio da hora, o poeta anseia pelo inatingível: "por outra coisa que o que chora"; e nesse anseio, o "eu" do poeta é atraído pelo turbilhão de coisas vagas e sonhadas, afastando-se de si mesmo - "o meu abandonar-se a mim próprio até desfalecer" - até reconhecer-se em uma recordação e esquecer-se - "e recordar tanto o Eu presente que me sinto esquecer". Após o pôr do sol, o "eu" do poeta é substituído por uma alienação total de si mesmo: "O Mistério sabe-me a eu ser outro... Luar sobre o não conter-se".

É relevante observar que já neste primeiro poema programático Pessoa introduz a problematização do "eu", que está perdido a ponto de esquecer-se. Em face disso, fortalece-se a alegação de que a problemática da identidade está intimamente relacionada às estéticas criadas por Pessoa, que são, por sua vez, tentativas de aperfeiçoar a arte do sonho. Na medida em que a arte deve, conforme o poeta português, ampliar a consciência humana de si e do mundo por meio do sonho (abstração, não ação), o Paulismo é apenas uma solução transitória, visto que, embora seja um poema modelo quanto ao vago, ao sutil e ao complexo, falta-lhe a nitidez e a plasticidade, características igualmente atribuídas à nova poesia portuguesa por Pessoa, e, por faltar-lhe objetivação (em oposição a sua subjetivação), tampouco consegue concretizar o poeta síntese, capaz de equilibrar a poesia subjetiva e objetiva e, consequentemente, explorar devidamente a problemática da identidade.

\subsection{Interseccionismo}

A segunda tentativa programática realizada por Fernando Pessoa de solucionar a evolução da criação poética moderna portuguesa, em especial a sua, foi o Interseccionismo, que é, por sua vez, uma evolução do Paulismo - ou "Paulismo a sério", como defende João Gaspar Simões -, pois, para o crítico, a estética pessoana trata de intercalar a realidade e o sonho. Simões (S/D) também sustenta erroneamente que o Interseccionismo é uma tentativa de representar na literatura o Cubismo e o Futurismo. A intersecção de planos

4 PESSOA, 1942 apud ARQUIVO PESSOA, [200-b?], não paginado. 
não pode derivar do Cubismo porque na estética pessoana é dada primazia ao sonho, não a realidade, como propõe o movimento cubista. Também não pode derivar do Futurismo, já que, tal qual o Paulismo, o Interseccionismo é uma estética abstrata e subjetiva, o oposto do que propôs Marinetti em seu manifesto futurista como a principal atitude do movimento, de ser uma arte com objetividade absoluta. Lind (1970), por outro lado, vê influência da técnica da fusão de Rimbaud ${ }^{5}$.

Segundo Hugo Friedrich (1978), encontra-se no poema "Marinha", de Rimbaud, o primeiro exemplo da técnica de fusão moderna. O poema apresenta dois campos semânticos diferentes, um marítimo (navio, mar) e outro terrestre (carro, charneca); mas eles estão de tal forma entrelaçados que um parece fundido no outro, de maneira que a distinção que normalmente os demarcaria como objetos reais é suprimida. A marinha é simultaneamente terra e vice-versa. Dessa forma, a técnica da fusão consiste na intersecção das coisas que, fundidas entre si, movem-se e trocam-se à vontade.

Friedrich afirma ainda que essa técnica é "um caso particular da desrealização da irrealidade sensível" (p. 86), pois "trata-se de uma não-realidade, de uma anulação das diferenças objetivas" (p. 86). Essa não realidade só é exprimível como uma fantasia superior à realidade, ou seja, como sonho. Novamente, retorna-se aqui a proposição sobre arte abstrata de Fernando Pessoa, para quem o poeta moderno é o poeta do sonho. A técnica da fusão é o que permite a Pessoa realizar a arte do sonho ${ }^{7}$.

A técnica da fusão é um dos vários elementos em comum entre poesia e pintura. Da mesma forma como a poesia, por meio da metáfora, realiza uma "transposição daquilo que é objetivo em imagens que não existem no mundo real” (FRIEDRICH, 1978, p. 87), também a pintura, por meio da "metamorfose", o faz. A técnica, portanto, concede plasticidade ao poema, justamente a característica buscada por Pessoa quando da criação do Interseccionismo e que, outrora, faltava no Paulismo.

Em consonância com Friedrich, Lind não entende a estética pessoana como uma doutrina propriamente dita, isto é, um conjunto coerente de ideias fundamentais a serem transmitidas, mas como uma técnica de composição, que compreende, de acordo com Ordoñes (1994), elementos das novas tendências. Também por isso, evita definir o Interseccionismo como Futurismo, como o faz Simões.

O Interseccionismo é o segundo estágio no caminho que levará ao projeto das "sensações", que, conforme Gonçalves (1995), servirá como justificativa dos heterônimos. Seu surgimento coincide com o aparecimento dos heterônimos, mesma época em que a circulação de ideias de vanguarda em Portugal atinge o auge com o retorno dos jovens

5 Jean-Nicolas Arthur Rimbaud foi um poeta simbolista francês que viveu na segunda metáde do séc. XIX.

6 "Carros de prata e cobre / Proas de aço e prata / Golpeiam a espuma, / Erguem touceiras de sarças. / As correntes da charneca, / E os sulcos imensos do refluxo, / Correm circularmente para o leste, / Para os pilares da floresta, / Para os fustes do dique, / Cujo ângulo é batido por turbilhões de luz."

O poema inicia com um verso que não condiz com o título, pois apresenta elementos terrestres, e segue com um verso mais adequado ao título, em que apresenta elementos marítimos. Inesperadamente, porém, tanto os carros como as proas, "golpeiam a espuma, erguem touceiras de sarças". É nesse trecho que a realidade concreta é subvertida dando lugar a uma não realidade. Além disso, segue a imagem das "correntes da charneca" e dos "sulcos do refluxo" que correm para os "pilares da floresta", aos "fustes do dique", todos inundados por "turbilhões de luz" que os impelem. Há uma equiparação absoluta dos elementos marítimos e terrestres que destrói a ordem concreta de maneira geral, subvertendo a realidade e alcançando um estado de sonho.

7 Não é possível afirmar se Pessoa conhecia ou não Rimbaud, já que cita apenas Mallarmé e Verlaine quando escreve sobre o Simbolismo francês. De certo, é possível perceber uma diferença fundamental entre os poemas "Marinha" e "Chuva oblíqua": o poema de Rimbaud não segue nenhum programa, ao contrário do poema de Pessoa, que é um modelo de um programa estético anteriormente elaborado. 
artistas radicados na França. A obra modelo do Interseccionismo, "Chuva oblíqua", é composto por seis poemas, considerados interseccionistas pelo próprio Pessoa, que intercalam a realidade vivida com o sonho, ou com uma realidade sonhada/inventada, ou com uma lembrança. Os princípios do vago, do sutil e do complexo estão presentes no texto, tal qual no poema modelo do Paulismo; além disso, as imagens dos poemas são claras, nítidas, e, por meio da técnica de fusão, de uma plasticidade facilmente perceptível. Já no primeiro poema que compõe "Chuva oblíqua" lê-se:

Atravessa esta paisagem o meu sonho dum porto infinito

E a cor das flores é transparente de as velas de grandes navios

Que largam do cais arrastando nas águas por sombra

Os vultos ao sol daquelas árvores antigas... (PESSOA, 1942 apud ARQUIVO

PESSOA, [200-c?], não paginado)

Conforme prevê o programa interseccionista, o poema baseia-se na intersecção de dois planos, uma paisagem vivida e um porto imaginado. Lind (1970) afirma que é desta intersecção que resulta uma sequência imagética de perceptível nitidez plástica. Ao contrário do que do que ocorre no poema de Rimbaud, em que são fundidos dois trechos do plano real, o poema modelo do programa é uma montagem em dois planos diferentes, de maneira que a sobreposição dos dois todos, o vivido e o sonhado, produz efeitos de contraste. O porto imaginado liberta o eu lírico da realidade. O sonho ganha espaço frente à realidade exterior, dessa maneira, a paisagem real assume a forma imaginária, surgindo como ficção, como em "os navios passam por dentro dos troncos das árvores" do poema, surge da dupla paisagem estática a imagem de uma nau que, mesmo sendo imaginária, assume privilégio de realidade e faz com que o eu lírico a perceba em ambos os planos simultaneamente: "e chega ao pé de mim, e entra por mim dentro, / e passa para outro lado de minha alma" ". A intersecção do sonho com a realidade proporciona no poema uma dupla vivência por parte do eu lírico, de modo que a distinção entre sonho e realidade fique quase apagada.

Da mesma forma no segundo poema do conjunto, a intersecção de planos valoriza o sonho: "Ilumina-se a igreja por dentro da chuva deste dia, / E cada vela que se acende é mais

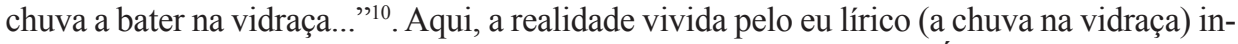
tercala-se com a realidade sonhada da Igreja preparada para a missa. É importante observar que a poesia é deliberadamente estática, pois o movimento sempre é uma decorrência da intervenção do sonho. Isso é digno de nota porque é a realização da ideia pessoana de que pensamento e ação, na idade moderna, estão separados irremediavelmente.

\section{O poeta e a arte do sonho}

No artigo intitulado "Apontamentos para uma estética não-aristotélica”, publicado na revista Athena ${ }^{11}$ atribuído a Álvaro de Campos, defende uma estática baseada na ideia de força e não de beleza. Pessoa chama de arte aristotélica toda arte cujo fim que se pretende é a beleza. Uma arte baseada na ideia de beleza pressupõe um ideal de belo (que pode estar tanto na felicidade quanto na infelicidade, como afirmara o filósofo grego), mas uma

8 PESSOA, 1942 apud ARQUIVO PESSOA, [200-c?], não paginado.

9 Idem.

10 Idem.

$111^{\text {a }}$ publ. in “Athena", no 3 e 4. Lisboa: Dez.-Jan. 1924-25 
arte baseada na ideia de força pressupõe uma capacidade de ação e reação, comumente encontrada em qualquer organismo vivo. O equilíbrio dessas duas forças é, portanto, vital para a vida. A partir disso, o poeta busca relacionar a ideia de força, provindo da capacidade de ação e reação com a arte, que, para ele, baseia-se na sensibilidade, que não é outra coisa para o poeta senão a própria vida da arte, por entender que a arte é feita "por se sentir e para se sentir". Assim, afirma:

Ora a arte, como é feita por se sentir e para se sentir — sem o que seria ciência ou propaganda - baseia-se na sensibilidade. A sensibilidade é pois a vida da arte. Dentro da sensibilidade, portanto, é que tem que haver a acção e a reacção que fazem a arte viver, a desintegração e integração que, equilibrando-se lhe dão vida. Se a força de integração viesse, na arte, de fora da sensibilidade, viria de fora da vida; não se trataria de uma reacção automática ou natural, mas de uma reacção mecânica ou artificial. (PESSOA, 1988, p. 171)

A partir disso, Pessoa conclui que para equilibrar as forças que operam sobre a sensibilidade, é preciso seguir o caminho inverso da estética aristotélica, que exige que o indivíduo generalize ou humanize a sua sensibilidade, ou seja, pressupõe que indivíduo universalize o que é particular e pessoal. Uma estética não-aristotélica deve pois seguir a ordem contrária: "é o geral que deve ser particularizado, o humano que se deve pessoalizar, o «exterior» que se deve tornar «interior»." (PESSOA, 1988, p. 172).

$\mathrm{O}$ artista que segue o modelo aristotélico subordina sua sensibilidade à sua inteligência, tornando-a humana e universal, no que isso tem de acessível e agradável. O artista nãoaristotélico, por sua vez, subordina tudo à sua sensibilidade por meio da inteligência, de modo a se tornar "um foco emissor abstracto sensível" que force os outros, queiram eles ou não, a sentir o que ele sentiu. É inegável que o artista não-aristotélico se propõe, então, a fazer com que os outros que percebem sua arte sintam também a sensação expressa no objeto artístico por ele elaborado.

A arte para Fernando Pessoa está intimamente ligada ao pensamento, ou seja, a verdadeira arte, segundo Pessoa (1988) é aquela que está subordinada ao domínio da inteligência, de modo que toda sensibilidade seja explorada através do pensamento racional. Dessa maneira, a pintura, a escultura, a arquitetura, por exemplo, são tidas como produtos incompletos de um desenvolvimento mental porque suas qualidades de visualização não estão subordinadas à inteligência. Assim, a literatura seria a única arte capaz de exprimir toda sensibilidade com um perfeito equilíbrio, pois as côa através da ideia. Partindo disso, Pessoa define arte como a expressão não das sensações, mas da nossa consciência das sensações, isto é, das sensações coadas pela inteligência.

Arte, bem definida, é a expressão harmônica da nossa consciência das sensações; quer dizer, nossas sensações precisam ser expressas de forma a criar um objeto que seja uma sensação para os demais. A arte não é, como disse Bacon, "o homem acrescentando à Natureza", trata-se da sensação multiplicada pela consciência - note bem, multiplicada. (PESSOA, S/D, p. 239-240)

Sua definição de arte passa pela distinção entre ação e pensamento, entendendo-se ambos como opostos. A ação está para a realidade assim como o pensamento está para a arte. Na definição de Pessoa, a arte é uma tentativa de construir uma realidade distinta daquela que as sensações do exterior e as sensações do interior sugerem. O fim da arte é, portanto, a organização das sensações do abstrato. Se a arte é "a expressão harmônica da nossa consciência das sensações” e seu o assunto é pura abstração, logo, observa-se que 
Pessoa entende que essa abstração é um conjunto de sensações, que não gera nenhuma ação. A abstração é, então, o sonho, em que não há ação, apenas a ideia. O sonho, para Pessoa, é a negação da ação. Esta ideia está claramente delimitada em um texto em que o poeta português define como é ou como deveria ser o poeta do sonho. Segue.

O poeta do sonho é geralmente um visual, um visual estético. O sonho é a vista geralmente. Pouco sabe auditivamente, tactilmente. E o "quadro", a "paisagem" é de sonho, na sua essência, porque é estática, negadora do continuamente dinâmica que é o mundo exterior. (Quanto mais rápida e turva é a vida moderna, mais lento, quieto e claro é o sonho.) (PESSOA, 1988, p. 178)

Nessa linha de raciocínio, quanto mais capacidade de sonho (relacionado a sensibilidade) um poeta tiver, melhor ele será, visto que partirá da ausência da ação, do que é estático, e sua arte será mais abstrata opondo-se à realidade concreta. Se a finalidade da arte é simplesmente "ampliar a autoconsciência humana" (PESSOA, 1988, p. 248), a arte tem, então, o "dever de se tornar cada vez mais consciente" (idem, p. 148). Quanto mais consciente, mais abstrata. Assim, entende-se a afirmação de Pessoa (p. 179): "o maior poeta da época moderna será o que tiver mais capacidade de sonho".

A definição da arte do sonho, abstrata, está ligada ao movimento Orpheu ${ }^{12}$. É na revista Orpheu que Pessoa publica a pela primeira vez O Marinheiro, em que a ação é substituída pelo pensamento, pela abstração. Por isso, o drama também pode ser caracterizado como não-aristotélico, visto que baseia-se antes na ideia de força, que de beleza, buscando particularizar as sensações. Nesse caminho, $O$ Marinheiro é leitura essencial, pois centraliza a discussão sobre a arte do sonho ao trazer o próprio sonho como tema central.

\section{Drama Estático: realização da estética não-Aristotélica}

A peça $O$ Marinheiro segue as mesmas diretrizes que norteavam o teatro simbolista no final do século XIX. Embora muitos críticos tenham se debruçado sobre o processo heteronímico deixando a obra dramática de Pessoa em segundo plano por suas características simbolistas, são justamente essas características que garantem, conforme Neves e Junqueira (2004), a eficácia das sugestões de um universo onírico, em especial a valorização de elementos sonoros e rítmicos, que repetidos acabam por compor uma linguagem poética. A linguagem poética e o universo onírico são também os responsáveis pela apresentação dos mistérios que envolvem a vida e a morte, a existência e a inexistência, diante dos quais a realidade se torna insignificante.

A peça ocupa o mesmo cenário do princípio ao fim, como já sugerido pelo subtítulo - "drama estático em um quadro" -, indicando desde o início a falta de ação que lhe é característica (daí ser definida como "drama em quadro", como uma imagem estática, e não em ato, o que faria pressupor a existência de ação). O cenário é um quarto em formato circular, na torre de um castelo, com uma única janela, da qual se avistam, ao longe, alguns montes e o mar. O próprio formato circular do quarto já indica uma certa circularidade que se refletirá na linguagem. O ambiente, isolado do mundo exterior, é tipicamente simbolista. No centro do quarto, sobre uma mesa, está o cadáver de uma donzela, rodeado por tochas acesas e por três veladoras, que dialogam sem sair do lugar que ocupam. $\mathrm{O}$ quadro se passa à noite, de modo que o espaço é vagamente iluminado pelas tochas e pelo luar que atravessa a janela.

12 Grupo de jovens escritores, pintores e entusiastas da arte que fundaram uma revista, Orpheu, para ilustrar e defender os valores estéticos da modernidade e proceder a uma intervenção na história da cultura de Portugal. 
A falta de noção de tempo somada à imobilidade das personagens, as pausas e os silêncios, provocam uma sensação de suspensão da vida. É a partir desse desprendimento do passado histórico, do presente real e do futuro possível, que se encontra ficcionalmente a capacidade de sonhar. É para este processo de desprender-se de si, que possibilita tanto às veladoras quanto ao marinheiro imaginar um passado não-real, que o leitor é convidado a integrar. A sugestão de um passado mítico, do marinheiro que constrói a pátria, remete ao arquétipo do navegador fundador, como o mito do herói grego Ulisses ter sido o fundador da cidade de Lisboa, explorado por Pessoa no poema "Ulisses", da obra Mensagem, em que se lê "Este que aqui aportou / Foi por não ser existindo. / Sem existir nos bastou." (PESSOA, 2006, p. 41)

Além dessa leitura mais convencional da peça, é preciso salientar também os aspectos que ultrapassam a estética simbolista e manifestam características marcadamente modernistas. Certamente o aspecto mais relevante diz respeito às personagens ensaiarem suas próprias ficções, como o fazem os heterônimos no "drama em gente", mas também é relevante observar que as personagens já questionarem o seu autor (na leitura possível do marinheiro como sonhador das veladoras) muito antes das seis personagens de Luigi Pirandello ${ }^{13}$, em 1921 na Itália. Além disso, a busca de uma arte baseada no sonho, na abstração, como forma de realização de uma arte baseada na ideia de força e não de beleza, reforçam a modernidade desta obra dramática.

É notável o fato de Pessoa ter escolhido O Marinheiro para aparecer como seu primeiro texto na revista Orpheu, quando é de conhecimento de todos que o poeta português já havia escrito parte considerável da poesia heteronímica. Isso dá mostras do seu apreço pelo drama estático, que permite a identificação de temas comuns à poética pessoana: o tédio, as dúvidas existenciais, a intersecção dos planos do real e do sonho, a autoconsciência, os desdobramentos do fingimento em arte, etc.

A peça é descrita como um drama em único ato; entretanto, Scherer (2003) lê O Marinheiro como tendo três momentos distintos: 1) do início da ação até a $13^{\mathrm{a}}$ fala da Segunda veladora: apresentação e introdução da irrealidade; 2) da $13^{\mathrm{a}}$ à $25^{\mathrm{a}}$ fala da Segunda veladora: narração do sonho do marinheiro; 3 ) da $25^{\text {a }}$ fala da Segunda veladora ao final da peça: horror e medo, anunciação do dia. O primeiro momento descrito por Scherer (2003) é responsável pela apresentação da ambientação da peça, em especial no que trata da caracterização do espaço-temporal (ou anticaracterização) e dos primeiros desdobramentos da questão do tempo, diretamente ligada ao elemento do sonho. Já nas primeiras falas das veladoras, percebe-se um tempo indefinido, pois parece não fluir para as veladoras.

PRIMEIRA VELADORA - Ainda não deu hora nenhuma.

SEGUNDA - Não se pode ouvir. Não há relógio aqui perto. Dentro em pouco deve ser dia. TERCEIRA — Não: o horizonte é negro. (PESSOA, 1988, p. 65)

Nesse simples diálogo, é revelado ao leitor um tempo que se arrasta sem acontecimentos, dominado pelo tédio e pela noite, no que este período tem de indefinição. Essa indefinição está também relacionada ao fingimento, explorado desde o início da peça. $\mathrm{Na}$ fala da Primeira veladora "Não desejais, minha irmã, que nos entretenhamos contando o que fomos? É belo e é sempre falso..." (PESSOA, 1988, p. 65) já se percebe a necessidade de fingir um passado. Cada uma das veladoras apresenta um relato de seu passado falso

13 É do dramaturgo Luigi Pirandello a peça intitulada "Seis personagens à procura de um autor", que relata um ensaio de teatro, que é invadido pelas personagens rejeitadas pelo criador e tentam convencer o diretor da companhia a encenar suas vidas. 
porque imaginário. Nesses relatos, é predominante um tempo indefinido. Tal como no gênero poético, o drama $O$ Marinheiro tem um tempo indefinido. Também o espaço é indefinido quando é sempre um outro espaço onde se situa a ação (o mar, a praia, etc.). A partir dessa indefinição do tempo e do espaço, Neves e Junqueira (2004) entendem que há na peça uma marcante dicotomia entre o "eu" e o "não-eu" expressa principalmente através do tempo e do espaço. O tempo do "eu" é o presente como se percebe, é o momento de proximidade com a morte no velório, marcado pela ausência de acontecimentos e preenchido apenas pelos sonhos das veladoras. O espaço do "eu" é o "lado de cá de todos os montes", é de vazio, de imobilidade, sem ação, sem mar, sem beleza, portanto, povoado de saudade do espaço e do tempo do "não-eu", ou seja, uma saudade do passado ("o que queremos ser queremo-lo sempre no passado"14) e do futuro ("aquele mar que nós vemos dá-nos sempre saudades daquele que não veremos nunca"15). Entretanto, como o passado não garantidamente foi, a memória do passado é de sonho, não da realidade. No decorrer do drama, o fingimento alcançará também o futuro (que é sonhado) e também o presente, a ponto de pôr em dúvida a própria existência das veladoras como realidade empírica.

Entre os relatos dos passados imaginários, há um trecho que revela íntima relação com a teoria da arte do sonho preconizada por Pessoa. A fala da Terceira veladora "As vossas frases lembram-me a minha alma..." (PESSOA, 1988, p. 69) tem como resposta da Segunda veladora uma frase emblemática "É talvez por não serem verdadeiras..." (ibidem). A arte do sonho pressupõe o fingimento de estados de alma para que o leitor sinta, não o poeta. Essa ideia é claramente expressa no diálogo das veladoras, compondo mais um indício de que $O$ Marinheiro concentra em si toda a discussão artística de Pessoa.

O segundo momento é dedicado ao relato do sonho com o marinheiro. Como introdução ao sonho, a Segunda veladora relata o momento em que teve o sonho:

Um dia que eu dei por mim recostada no cimo frio de um rochedo, e que eu tinha esquecido que tinha pai e mãe e que houvera em mim infância e outros dias - nesse dia vi ao longe, como uma coisa que eu só pensasse em ver, a passagem vaga de uma vela. Depois ela cessou... Quando reparei para mim, vi que já tinha esse meu sonho... (PESSOA, 1988, p. 71-72)

O sonho surge num momento de completo esquecimento da vida real, em uma atmosfera mágica. Sem saber explicar de onde veio o sonho, a Segunda veladora sabe apenas que o seu estado ao criá-lo era de total desprendimento de uma identidade particular. Esse fato elucida a dedicação das veladoras em imaginar passados falsos para desviarem dos seus passados reais e, ao mesmo tempo, elucida também o próprio processo de fazer poético de Pessoa, que busca realizar o processo criativo conforme uma outra consciência, tudo por meio da racionalidade, da inteligência.

O sonho relatado é simples: um marinheiro náufrago, sofrendo por não poder retornar à pátria, cria uma pátria imaginária e, com o passar do tempo, não consegue mais lembrar sua verdadeira pátria, apenas a imaginada. Há uma identificação das demais veladoras, mas é o leitor quem percebe uma identificação mais aterrorizante: assim como o marinheiro criou um passado imaginário e não conseguiu mais distinguir o real do sonho, também as veladoras criaram passados imaginários e podem ter o mesmo fim.

É no terceiro momento descrito por Scherer (2003) que a máxima tensão se revela: após o relato do sonho do marinheiro, a tensão da incerteza do que é realidade e do que

14 PESSOA, 1988, p. 71.

15 Idem, p. 67. 
é sonho acomete a cada uma das veladoras. Há uma clara tentativa de intersecção dos planos da realidade e do sonho. Se no plano da realidade as veladoras falam de um sonho com um marinheiro que cria uma pátria imaginária, no plano do sonho o marinheiro é retratado como o criador (enquanto imaginador) das veladoras. A história do marinheiro que cria um novo passado apresenta as mesmas características das histórias das de vida das veladoras, que também têm criado outros passados, como revelam antes da narrativa do sonho. Assim como o marinheiro confunde o sonho da pátria imaginada com a realidade passada, não conseguindo mais distinguir o passado real do sonho, também as veladoras começam a duvidar do que é real e do que é sonho em suas vidas. O marinheiro está aprisionado em seu sonho, e esta agonia impregna também as veladoras que terminam o drama aflitas por não saberem ao certo que coisas existem de fato e que coisas são apenas sonhos. Por fim, sem poderem afirmar o que é sonho e o que é real, o sonho acaba por parecer mais real do que a própria vida. Scherer (2003) entende que todos os elementos desse drama estático, a saber, a estaticidade, a atividade de contar/imaginar e o tempo indefinido, estão ligados a um eixo: o sonho, e só têm presença no drama em função dele. Sendo o sonho o principal eixo temático do drama, atinge-se, nesse ponto, uma perfeita intersecção dos dois planos (realidade e sonho), de modo que o sonho torna-se fundamental para as veladoras, pois as eleva para além das questões de vida e morte.

No texto, três jovens passam a noite velando uma quarta jovem e, nesse período, não executam nenhuma ação além do ato de dizer. Segundo Neves e Junqueira (2004), a única movimentação no drama é "a da imaginação das personagens, expressa pela conversa que elas travam entre si - pela linguagem” (p. 189). Portanto, no drama estático o ato de dizer é a única ação existente, mas não tem por finalidade representar as ações humanas, seu fim é antes representar as sensações fingidas, o abstrato, o sonho. Sem ação, o drama explora ao máximo uma tensão intelectual com o objetivo de ser uma arte baseada na ideia de força, envolvendo a abstração, o sonho, a não-ação.

Em sua teoria dos atos de fala, Austin (1990) contextualiza na ação a análise da linguagem, entendendo a linguagem como uma forma de ação ("todo dizer é fazer") e não apenas de representação da realidade, e distingue dois tipos de enunciados: os constatativos e os performativos. Os enunciados constatativos são aqueles descrevem ou relatam um estado de coisas, como a expressão "ele prometeu", e, por referirem-se a dados objetivos (isentos de deformações), submetem-se ao critério de verificabilidade, isto é, podem ser classificados como verdadeiros ou falsos. Na prática, os enunciados constatativos ainda estão no âmbito da linguagem como representação da realidade. Os enunciados performativos, por sua vez, não descrevem, não relatam, nem constatam absolutamente nada, não podendo ser analisados quando à verdade ou a falsidade, mas quanto às condições de sucesso. Escapam, portanto, à constatatividade. Nesse caso, o simples fato de enunciar equivale a concluir aquilo que foi enunciado. A promessa é um exemplo notável desse tipo de enunciado, visto que dizer "eu prometo" é prometer efetivamente, ou seja, comprometer-se a fazer mais tarde por outra pessoa o que é dito no enunciado. Essa característica de "fazer-dizendo" só é possível quando expressa por verbos na primeira pessoa do indicativo, para marcar o comprometimento do "eu" com a promessa. Enunciados desse tipo são em si a realização de uma ação, daí serem denominados por Austin (1990) de performativos, derivação do verbo inglês to perform, indicando que "ao se emitir o proferimento está-se realizando uma ação, não sendo, consequentemente, considerado um mero equivalente a dizer algo" (p. 25).

É necessário observar, entretanto, que o fato de proferir um enunciado performativo não é garantia de sua realização, tendo em vista que a ação por ele designada somente se 
realizará de fato se as circunstâncias forem adequadas. Em circunstâncias inadequadas, o enunciado performativo resulta sem efeito, ele fracassa. Para que um enunciado performativo seja bem-sucedido, Austin elencou os critérios que precisam ser satisfeitos, aos quais chamou de "condições de felicidade". São eles:

1. Deve existir um procedimento convencionalmente aceito, que apresente um determinado efeito convencional e que inclua o proferimento de certas palavras, por certas pessoas, e em certas circunstância; e além disso, que

2. as pessoas e circunstâncias particulares, em cada caso, devem ser adequadas ao procedimento invocado.

3. O procedimento tem de ser executado, por todos os participantes, de modo correto e

4. completo.

5. Nos casos em que, como ocorre com frequência, o procedimento visa às pessoas com seus pensamentos e sentimentos, ou visa à instauração de uma conduta correspondente por parte de alguns dos participantes, então aquele que participa do procedimento, e o invoca deve de fato ter tais pensamentos ou sentimentos, e os participantes devem ter a intenção de se conduzirem de maneira adequada, e, além disso,

6. devem realmente conduzir-se dessa maneira subsequentemente. (AUSTIN, 1990, p. 31)

Se alguma dessas seis regras for transgredida, o proferimento performativo será malogrado (ou, nas palavras de Austin, "infeliz"). Assim, se um faxineiro proferir "Eu voz declaro marido e mulher", o performativo não se realiza (isto é, o casamento não é efetivado) porque o faxineiro não possui autoridade para realizar o casamento. Logo, o enunciado do faxineiro é nulo. Da mesma, se as pessoas não estão em posição de realizar o ato porque, por exemplo, já estão casadas, o ato em questão (casamento) não se efetua.

Sendo necessário que as circunstâncias em que as palavras forem proferidas sejam apropriadas (AUSTIN, 1990), é o contexto de produção de cada fala que define, portanto, tratar-se de um ato de fala performativo. Para compor esse contexto, Pessoa cumpre as condições apresentadas por Austin (1990) para que o ato performativo tenha validade: 1) apresenta um procedimento convencionalmente aceito - não há dúvida quanto ao entendimento do ato de imaginar/sonhar e do ato de relatar algo imaginado/sonhado como prática social -;2) apresenta personalidades, as veladoras, e circunstâncias adequadas ao procedimento; 3 ) todos os participantes do drama executam o procedimento da imaginação/sonho de maneira adequada e 4) completa, tendo cada veladora imaginado um passado diferente para si; 5) elabora minimamente o caráter de cada personalidade; e 6) essas personalidades seguem conduzindo-se dessa maneira subsequentemente.

O marinheiro é uma primeira realização por Pessoa do drama estático, que terá sua máxima concretização com a criação heteronímia, quando o teatro serve como um "molde oco", como propõe Moisés (1988), para o conteúdo essencialmente poético dos heterônimos e do poeta ortônimo, ele mesmo transformado em elemento do drama em gente. Neves \& Junqueira (2004) afirmam que é preciso reavaliar as reflexões de Fernando Pessoa sobre teatro como ponto de partida da concepção vanguardista do seu "drama em gente". Elas, assim como Maria Teresa Rita Lopes (1985), identificam as personagens de $O$ Marinheiro como sombras embrionárias dos três heterônimos, pois tanto o drama estático quanto a heteronímia partem de um mesmo procedimento de criação dramática.

As veladoras têm temperamentos muito parecidos, não diferem muito umas das outras. No entanto, é possível delinear algumas características de cada uma baseando-se em seus atos de dizer como reveladores do seu caráter. A Segunda veladora é quem revela o sonho do marinheiro e também é, segundo Scherer (2003), a que possui caracterização 
psicológica mais definida. É ela quem toma mais iniciativa, quem se entrega a invenção do sonho e abre caminho da sensibilidade do sonho para as demais veladoras. A Terceira veladora parece ser mais ligada à objetividade, já que é ela quem indica o início da noite, a cor do horizonte, e também apela para a realidade da passagem do tempo. É, portanto, a mais racional. A Primeira veladora, por sua vez, é a mais melancólica. Para ela tudo é triste, almeja sempre uma realidade outra que não a sua, quer ter tido o sonho em lugar da Segunda veladora, quer ter vivido como outro. A Primeira veladora tende ao desespero e a fragilidade. Mesmo assim, as veladoras ainda não parecem ter existências separadas.

O personagem marinheiro pode ser lido como o criador das personagens veladoras (no plano do sonho), tal como um poeta dramático, que cria as personagens veladoras que, por sua vez, têm vida própria. Nessa ótica, $O$ marinheiro aparece como um ensaio para a heteronímia, já que se configura como um drama sem atos, mas composto de monólogos poéticos. Pessoa pensou os heterônimos como um dramaturgo pensa os personagens, e chamou a heteronímia de drama em gente justamente por estabelecer relações entre esses personagens, mas essas relações são essencialmente poéticas. Por similaridade, pode-se supor que as veladoras são um ensaio para a gênese dos três famosos heterônimos, sendo a Segunda veladora um embrião de Alberto Caeiro, a Terceira veladora um embrião de Ricardo Reis, a Primeira veladora um embrião de Álvaro de Campos.

A diferença entre o drama estático e a criação heteronímia é, segundo Lopes (1985), que no drama estático percebe-se a coexistência do plano da realidade e do plano da ficção, ou seja, do plano das veladoras - as criadoras - e do plano do marinheiro sonhado - a criatura; enquanto no fenômeno heteronímico, ao contrário, o que se observa é que esses planos se descolam e que a ficção evolui praticamente sozinha, independentemente de seu autor, já que cada heterônimo torna-se também um autor. Portanto, em O Marinheiro já há indícios representativos de um modernismo que vai além do desejo de substituir a realidade pela irrealidade: ao optarem as veladoras pelo espaço do não-real, pelo mundo onírico, elas "assumem o fingimento como princípio determinante da sua conduta e, afinal, da sua identidade mesma” (NEVES; JUNQUEIRA, 2004, p. 194).

\section{Considerações Finais}

O Marinheiro apresenta, embora encoberta, uma forte reflexividade discursiva. Essa característica se manifesta duplamente, no nível do enunciado, quando as personagens se questionam, e no nível da enunciação, quando as vozes se confundem com a voz autoral, enquanto instância elocutória exterior à própria estrutura da peça. Por conta disso, torna instáveis as categorias antes estáveis: o autor e a personagens, a ficção e a realidade, a identidade e a alteridade, passado e presente. Na peça, essas categorias são indistinguíveis, pois, conforme Gagliardi (2011), aparecem trocadas em um jogo ilusório.

No drama estático, a memória deixa de ser um registro, é construída por meio do sonho. Assim, o passado e o presente assumem outro sentido, não mais estável. Enquanto o passado confunde-se entre memória e sonho, o presente flutua entre a realidade do aqui e agora e um outro espaço, um espaço do outro, e um tempo indefinido.

O Marinheiro assume as características da arte do sonho, busca transportar o leitor também para um estado de suspensão da vida, para o abstrato, de modo que ele também sinta. O leitor é forçado a unir os diversos elementos, as múltiplas situações de sonho, em um todo significante, adquirindo um caráter ativo de ser também sonhador, enquanto criador do próprio texto. A sutileza, o vago e a complexidade presentes no texto reforçam 


\section{Conexão Letras}

ainda mais as características da arte do sonho almejada por Pessoa e já ensaiada nos programas paúlico e interseccionista (sendo o poema "Chuva Oblíqua" também publicado na revista Orpheu). Dessa forma, O Marinheiro concretiza-se como exemplar de uma estética não-aristotélica e, como drama estático, um ensaio para o "drama em gente".

\section{Referências}

ANDRADE, Débora Oliveira. Elementos do drama em O marinheiro. In: Todas as $\mathrm{Mu}$ sas. Ano 01, no 01, 2009, p. 150-158.

ARQUIVO PESSOA. Hora absurda. [S. 1], [200-a?]. Disponível em: <http://arquivopessoa.net/textos/829>. Acesso em: 28 de set. 2015.

. PAUIS. [S. 1], [200-b?]. Disponível em: <http://arquivopessoa.net/textos/829>.

Acesso em: 28 de set. 2015.

. Chuva Oblíqua. [S. 1], [200-c?]. Disponível em: $<$ http://arquivopessoa.net/textos/829>. Acesso em: 28 de set. 2015.

ARISTÓTELES. Arte Poética. São Paulo: Martin Claret, 2003.

AUSTIN, John Langshaw. Quando dizer é fazer: palavras e ação. Porto Alegre: Artes

Médicas, 1990.

FRIEDRICH, Hugo. Estrutura da lírica moderna - da metade do século XIX a meados do século XX. São Paulo: Duas Cidades, 1978.

GAGLIARDI, Caio. A reflexividade discursiva em $O$ Marinheiro, de Fernando Pessoa. In: Pitágoras, nº 500, vol. 1, 2011, p. 97-118.

GONÇALVES, Robson Pereira. O sujeito Pessoa: literatura e psicanálise. Santa Maria: Ed. UFSM, 1995.

LIND, Georg Rudolf. Teoria poética de Fernando Pessoa. Porto: Editorial Inova, 1970. LOPES, Maria Teresa Rita. Fernando Pessoa et le drame symboliste: héritage et création. Paris: Fondation Calouste Gulbenkian, 1985.

MOISÉS, Massaud. Fernando Pessoa: o espelho e a esfinge. São Paulo: Círculo do Livro, 1988.

NEVES, Maria Helena de Moura; JUNQUEIRA, Renata Soares. O estatuto da linguagem n'O marinheiro de Fernando Pessoa. In: SCRIPTA, Belo Horizonte, v. 7, n. 14, 2004, p. 183-201.

PESSOA, Fernando. Páginas íntimas e de auto-interpretação. Lisboa: Ática, 1966. . Páginas de Estética e de Teoria Literárias. Lisboa: Ática, 1966.

. O banqueiro anarquista e outras prosas. São Paulo: Editora da Universidade de São Paulo, 1988.

. Mensagem: obra poética I. Porto Alegre: L\&PM, 2006.

PIRANDELLO, Luigi. Seis personagens à procura de um autor. In: . Teatro I. Rio de Janeiro: Civilização Brasileira, 1972. P. 1-118.

SCHERER, Telma. Exercícios do tempo: Dias Felizes e Esperando Godot, de Samuel Beckett; $O$ Marinheiro, de Fernando Pessoa. Dissertação (Mestrado em Letras). Universidade Federal do Rio Grande do Sul, 2003.

SIMÕES, João Gaspar. Vida e obra de Fernando Pessoa: história duma geração. Lisboa: Bertrand, s/d. 